\title{
Quality Assurance Criteria for Waste Isolation Pilot Plant Performance Assessment
}

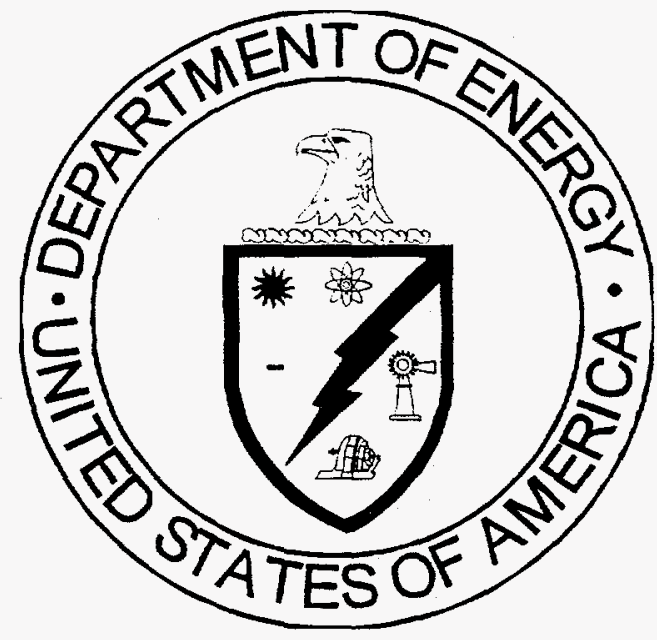

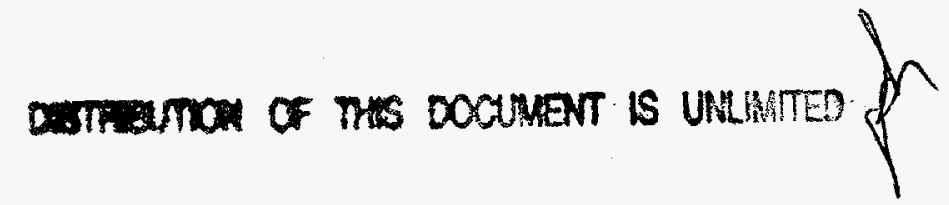

\section{July 1995 \\ Prepared for

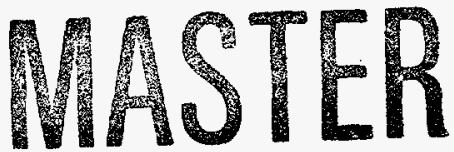 \\ United States Department of Energy}

Westinghouse Electric Corporation Waste Isolation Division 


\section{DISCLAMMER}

Portions of this document may be illegible in electronic image products. Images are produced from the best available original document. 


\section{DISCLAIMER}

This report was prepared as an account of work sponsored by an agency of the United States Government. Neither the United States Government nor any agency thereof, nor any of their employees, make any warranty, express or implied, or assumes any legal liability or responsibility for the accuracy, completeness, or usefulness of any information, apparatus, product, or process disclosed, or represents that its use would not infringe privately owned rights. Reference herein to any specific commercial product, process, or service by trade name, trademark, manufacturer, or otherwise does not necessarily constitute or imply its endorsement, recommendation, or favoring by the United States Government or any agency thereof. The views and opinions of authors expressed herein do not necessarily state or reflect those of the United States Government or any agency thereof. 
This document has been reproduced directly from the best possible copy. It is available to DOE and DOE contractors at the following address:

Office of Scientific and Technical Information

P. O. Box 62

Oak Ridge, TN 37831

Prices available from (615) 576-8401

Available to the public from the

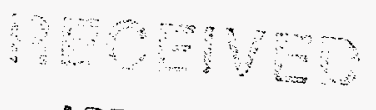

APS 033097

National Technical Information Service

Q8.

U. S. Department of Commerce

5285 Port Royal Road

Springfield, VA 22161

Processing and final preparation of this report was performed by the Waste Isolation Pilot Plant Management and Operating Contractor for the U.S. Department of Energy under Contract No. DE-AC0486AL31950. 


\section{Table of Contents}

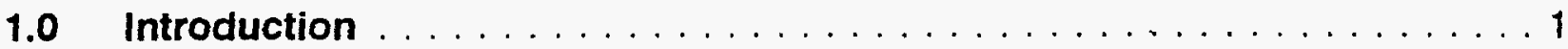

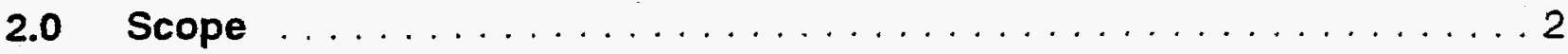

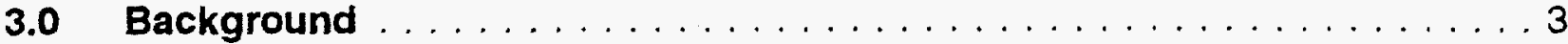

3.1 Validation and Verification - General .............

3.2 Validation and Verification-A Redefinition $\ldots \ldots \ldots \ldots \ldots$

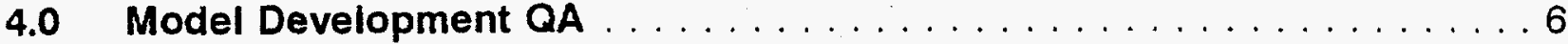

4.1 Model Development - General Process $\ldots \ldots \ldots \ldots \ldots$

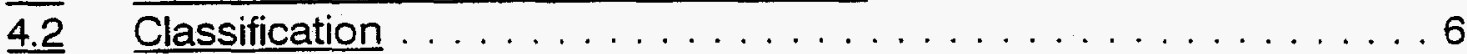

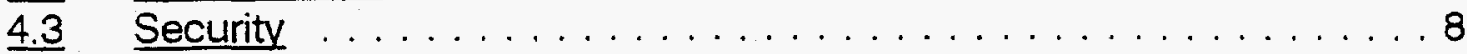

4.4 Personnel Responsibilities $\ldots \ldots \ldots \ldots \ldots \ldots \ldots \ldots$

4.5 Verification . . . . . . . . . . . . . . . . . 11

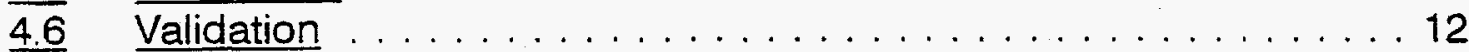

4.7 Model Documentation $\ldots \ldots \ldots \ldots \ldots \ldots \ldots \ldots \ldots$

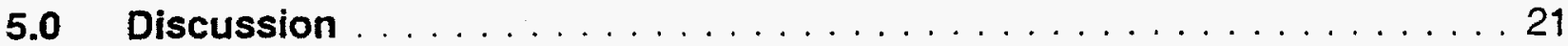

6.0 Recommendations and Future Plans $\ldots \ldots \ldots \ldots \ldots \ldots$

Processing and final preparation of this report was performed by the Waste Isolation Pilot Plant Management and Operating Contractor for the U.S. Department of Energy under Contract No. DE-ACO4-86AL31950. 


\section{List of Appendices}

Appendix A - List of Applicable References 


\section{List Of Acronyms}

ANSI/IEEE American National Standards Institute/Institute of Electrical and Electronics Engineering

ASME American Society of Mechanical Engineering

CAMCON Compliance Assessment Methodology CONtroller

CFR

Code of Federal Regulations

DOE

Department of Energy

EPA Environmental Protection Agency

IAEA International Atomic Energy Agency

NWTD Nuclear Waste Technology Department

QA Quality Assurance

QC Quality Control

SMS Software Management System

SNL Sandia National Laboratories

SWCF Sandia National Laboratories Waste Isolation Pilot Plant Central Files

TRU Transuranic

USGS United States Geological Survey

WIPP Waste Isolation Pilot Plant 


\section{Quality Assurance Criteria for Waste Isolation Pilot Plant Performance Assessment Modeling}

\subsection{Introduction}

The U.S. Department of Energy (DOE) is developing the Waste Isolation Pilot Plant (WIPP) as a deep geologic repository for transuranic (TRU) and TRUmixed wastes generated by DOE Defense Program activities. Regulatory agencies, including the Environmental Protection Agency (EPA) and New Mexico Environment Department, will be forced to rely upon system modeling to determine the potential compliance of the WIPP facility with federal regulations. Specifically, long-term modeling efforts are focused on compliance with 40 CFR Part 268, "Land Disposal Restrictions," and 40 CFR Part 191, "Environmental Radiation Protection Standards for Management and Disposal of Spent Nuclear Fuel, High-Level, and Transuranic Radioactive Wastes." DOE plans to use the similar conceptual models and numerical codes to demonstrate compliance under both of these regulations. Sandia National Laboratories (SNL) has been developing a system model ${ }^{1}$ that will be used to demonstrate potential waste migration from the WIPP facility. Because the geologic system underlying the WIPP site is not completely understood, the software code to model the system must be developed to exacting standards for its predictions to be reliable and defensible. This is a complex model that consists of many submodules used to describe various migration pathways and processes that affect potential waste migration. 


\subsection{Scope}

DOE requirements for quality assurance (QA) programs are described in 10 CFR § 830.120, "Quality Assurance Requirements" (59 FR 15843). OA programs are defined in reference to computer software in DOE Order 1330.1D, Computer Software Management. The QA program, under which the model is being developed, must be able to withstand the same level of scrutiny as the model itself. QA programs have two elements; $Q A$ and quality control $(\mathrm{QC})$. DOE Order 1330.1D defines $\mathrm{QA}$ as, "A planned and systematic pattern of all actions necessary to provide adequate confidence that the item or product conforms to established operations, functions, and technical requirements." $\mathrm{QC}$ is defined as, "An evaluation to ensure that a final product conforms to established operational, functional, and technical requirements."

Although DOE Order $1330.1 \mathrm{D}$ requires software developers and users to implement software management methodologies, this report focuses on only the $Q A / Q C$ requirements associated with software development. In addition, this report identifies the industry standard for model QA programs, but it does not address the QA requirements for model input data.

Many organizations have also developed QA program standards for software development and use that may be applied to computer models.

Recommendations and direction for properly implementing a QA program are available from the EPA, the DOE, the American Society of Mechanical Engineers (ASME), the International Atomic Energy Agency (IAEA), and the American National Standards Institute/Institute of Electrical and Electronics Engineers (ANSI/IEEE). The United States Geological Survey (USGS) provides suggestions for model documentation, which is an important part of a model QA program. The evolution of the SNL model for use in the WIPP performance assessment has followed the SNL WIPP-specific QA procedures for software development and analyses (SNL 1992; SNL 1991). This report presents the QA program elements recommended by EPA, DOE, ASME, IAEA, ANSI/IEEE, and others, and compares these to the SNL WIPP performance assessment QA program. 


\subsection{Background}

\subsection{Validation and Verification - General}

During software development, $\mathrm{QA}$ is primarily concerned with the validation and verification of the software. Unfortunately, the definitions of both validation and verification are ambiguous.

\subsubsection{Validation}

Validation has been defined by various organizations as:

- The comparison of model results with numerical data independently derived from laboratory experiments or observations of the environment (EPA 1991)

- The test and evaluation of the completed software to ensure compliance with software requirements (ASME 1990)

- The process which determines whether the mathematical model represents the intended process or system acceptably (ASME $1989 b$ )

- The process of evaluating software at the end of the software development process to ensure compliance with software requirements (ANSI/IEEE 1986 and DOE Order 1330.1D)

- The process of comparing field and experimental data with model results to ensure that the conceptual model and the mathematical code represent the system processes accurately (IAEA 1989)

- The process of assuring through sufficient testing with site-specific data that a conceptual model and the corresponding mathematical and computational models correctly predict a physical process with sufficient accuracy based on current knowledge (SNL 1992). 


\subsubsection{Verification}

Verification has been variously defined as:

- Examination of the code used to solve the governing equations for accuracy and operational correctness (EPA 1991)

- The method of evaluating the latest version of a computer code to determine whether it fulfills the requirements established during the previous software development cycle (ASME 1990; DOE Order 1330.1D; ANSI/IEEE 1986)

- The process of determining whether or not the products of a given phase of the software development cycle fulfill the requirements established during the previous phase (DOE Order 1330.1D)

- The process which demonstrates that the software correctly performs its stated capabilities and functions (ASME 1989b)

- The method of comparing similar codes' results or comparing codes to analytical solutions to ensure that the mathematical model implemented in the computer code accurately represents the conceptual model (IAEA 1989)

- The process of assuring that the code correctly performs the stated capabilities (e.g., solves the equations in the mathematical model) (SNL 1991)

\subsection{Validation and Verification - A Redefinition}

3.2.1 For the purposes of this report, the definitions can be simplified and combined as the following statements:

- Validation is ensuring that the completed software performs the proper analysis for a particular application and is appropriate for the processes in that system. 
Quality Assurance Criteria for WIPP

DOENIPP-95-2050

Performance Assessment Modeling

Page 5 of 26

- Verification is ensuring that the individual portions of the mathematical model correctly perform the calculations specified by the numerical algorithm(s).

3.2.2 A viable model $Q A$ program entails more than defining these terms or performing these operations. Section 4 describes model QA programs in detail. 


\subsection{Model Development OA}

\subsection{Model Development - General Process}

4.1.1 Proper model QA programs consist of classifying the software (optional), establishing procedures to assure security of the model, establishing responsibilities for individuals participating in the development of the model, verifying and validating the model being developed, and documenting the model development. To produce the most useful and defensible computer models, model development should systematically include all of these elements so that $Q A$ activities are an integral part of the development process.

4.1.2 In the following sections, various aspects of model $Q A$ are discussed in relation to techniques proposed by various organizations and methods followed by SNL in the development of computer-based models for WIPP.

\subsection{Classification}

4.2.1 One aspect of model $Q A$ is establishing a classification system for software being developed or used at a site. Adopting such a system, although optional, permits establishing definitive criteria for quality levels on which model review and approval requirements can be based. Such a system defines the rigor of the validation and verification of the model, the degree of confidence that can be placed in the model output, and the potential internal distribution of the developed model.

4.2.2 ASME (1989b) presents guidance for determining and using QA program classification and grading factors, which can be adapted for model development. The quality levels should be based on definitive criteria, including the software's importance in determining regulatory compliance and the results of analyses that use the software.

SNL has established a classification system for software in development, and for the analyses to be conducted using that software, that addresses 
the guidance contained in ASME 1989b (SNL 1991; SNL 1992). This system includes the following four software classes (SNL 1991):

1. Class A (Adjudication)

This software has full QA status and satisfies the SNL QA requirements for traceability, retrievability, documentation, and verification. Software with this classification is available to any interested user within the WIPP project group at SNL.

2. Class C (Candidate)

Software with this classification has partial QA status and may be undergoing continued refinement. Class $C$ software is a candidate for Class $A$, but currently satisfies only the traceability and retrievability requirements; the documentation and verification has not been formally evaluated. Class $C$ software is often being revised to adapt the software's capability to a changing environment and is available to any interested user within the WIPP project group at SNL.

3. Class D (Deleted)

Obsolete software that was formerly Class A or Class C. Class D software is usually archived because a more sophisticated version has superseded its use. If necessary, Class $D$ software can be retrieved from the archives.

4. Class $X$ (Experimental)

Entry-level software in the first stages of development or experimentation. This software meets no $Q A$ requirements, is in the early stages of development, and has not yet been processed through any formal $Q A$ procedures. Usually, a potential user of Class $X$ software must obtain the software by contacting the software developer.

Because the SNL models will be used to demonstrate regulatory compliance with 40 CFR Parts 191 and 268, they must meet Class A OA 
requirements.

\subsection{Security}

4.3.1 Providing security for the model is an important aspect of model development QA. ASME (1989a) includes requirements for design control, which includes controlling changes to final designs of an item. ASME (1990) requires that changes to software be formally documented and that computer systems be controlled to prevent unauthorized access. DOE Order $1330.1 \mathrm{D}$ requires that appropriate security activities be carried out and that procedures are in place to ensure the security of software during the development process.

4.3.2 SNL provides for a Software Management System (SMS) for all Class A, C, and D software (SNL 1991). The SMS consists, in part, of a repository for current versions of all software for use by SNL personnel working on the WIPP project. This software is provided with "execute only" access. An individual is assigned the duties of "Code Sponsor" (see next section), which includes entering the software in to the SMS. This individual is also responsible for controlling any changes to the software.

\subsection{Personnel Responsibilities}

4.4.1 Specific organizational structures for model development and QA have not been mandated by regulatory agencies or proposed as standards by organizations such as ASME and ANSI/IEEE. Therefore, organizational structures may be specifically designed for a particular task, provided the organization effectively implements the elements of a good QA program. Typically, model application is the responsibility of the project manager and model verification and validation are assigned to individuals qualified to perform those activities.

4.4.2 Individual roles for model $Q A$ should be delineated in the QA project plan. For each individual involved, the duties, levels of responsibility, and accountability should be clearly described. It is important that the following duties be included (SNL 1991): 
A] Training - including orientation, documentation, review, and updating

B] Procurement of items and services

C] Documentation - including preparation, review, issuance, revision, and archiving of documents associated with the model development process

D] Computer software control - including applicability and evaluation; revision/modification; development; and data integrity

E] Oversight of implementation - including assessment and corrective action.

4.4.3 The SNL model QA program implements QA procedures through eight participants:

1. Nuclear Waste Technology Department (NWTD) QA manager

2. Performance assessment QA coordinator

3. SNL WIPP central files (SWCF) manager

4. Code review committee

5. Code sponsor

6. Code consultant

7. Task leader

8. User.

4.4.4 Responsibilities of these personnel are outlined as follows (SNL 1991):

1. NWTD QA Manager: The NWTD QA manager ensures the WIPP model $Q A$ program and the corresponding QA procedures are 
established, executed, and maintained. As part of this responsibility, the NWTD QA chief conducts audits (either directly or through an audit team) of the performance assessment software development process at SNL.

2. Performance Assessment QA Coordinator: The performance assessment $Q A$ coordinator oversees and ensures implementation of the model QA process.

3. SWCF Manager: The SWCF manager properly files documentation of software development and makes it available to users.

4. Software Code Review Committee: Appointed by the performance assessment $Q A$ coordinator, the committee determines whether the documentation (internal and external) and verification for scientific/engineering software meet the SNL model QA standards for Class A software.

5. Code Sponsor: The code sponsor guides the software code through the model QA procedures for the WIPP performance assessment. This individual is also responsible for entering the model into the SMS and controlling any changes to the model.

6. Code Consultant: The code consultant (ideally, but not necessarily, the author of the software) provides technical expertise on the mathematical and numerical bases and application of the software.

7. Task Leader: The task leader conducts projects described in the SNL work plan for the WIPP, including developing and using software. These responsibilities include specifying software coding and structure requirements, outlining the tests and inspections necessary for accepting the software, designating code sponsors and code consultants (if necessary) to participate in the project, and determining compliance with model QA procedures.

8. User: The user ensures a particular software provides a quality analysis. This includes all aspects of actual use, including inputting 
data, running the model, and interpreting output, that may affect the quality of the analysis provided by the code, and communicating results or problems to the appropriate personnel responsible for the code.

\subsection{Verification}

4.5.1 Verification is conducted to ensure that the individual portions of the mathematical model correctly perform the calculations specified by the numerical algorithm(s). Verification is performed during each phase of the model's development to ensure the correctness and accuracy of the computational algorithms used to solve the governing equations and that the computer code is fully operational (EPA 1991).

4.5.2 The model is verified by conducting tests of the algorithms during each phase of model development. The results of these tests are then compared to results of hand calculations, calculations using comparable proven computer programs, or empirical data and information from technical literature (ASME 1989a). Verification may also be accomplished through technical reviews and other analyses (ANSI/IEEE 1987). Verification should be performed by persons other than those who developed the software (ASME 1990).

4.5.3 The SNL OA program addresses this issue by stating that computer models will be verified according to the complexity of the code. Simple codes may be adequately verified by comparing the results of the tests to hand-calculated numbers. Complex codes may require one or more of the following verification methods (SNL 1991):

- Performing extensive numerical tests and comparing the results with analytic solutions

- Benchmarking the code against other verified software

- Using the code in parameter sensitivity studies. 


\subsection{Validation}

4.6.1 Following completion of model development or modification, the model must be validated before use. Whether or not a model is valid for a particular application is determined by comparing its performance to performance criteria established by the potential user; use of these criteria establishes the following three levels of validity (EPA 1991):

1. Statistical validity - Statistical measures are used to check agreement between the model result distribution and a measured data distribution. Validity is established for single variable models by using an appropriate criterion for result accuracy. For multiple variable models, statistical validity can be measured using a multivariate analysis of variance.

2. Deviative validity - A deviation coefficient can be established in the absence of enough data to perform statistical validation. The deviation coefficient could be the sum of relative deviations. For multivariate models, deviative validity can be measured using a deviation coefficient that is the distance between two vectors in multidimensional space.

3. Qualitative validity - A qualitative scale is used for validity (e.g., excellent, good, fair, poor) based on expert subjective judgment. Qualitative validity is often established by comparing graphs of calculated and measured data. For multiple variable models, qualitative validity can be established one variable at a time using a series of graphs.

\subsubsection{The level of validity possible or desired depends on the type of} validation testing performed and the resources available to perform the validation as well as the circumstances surrounding the situation to be modeled. A model to be used for screening variables and scenarios does not need to be validated as rigorously as does a model that will establish compliance. Statistical validity is the most rigorous and requires the most resources. The validation required for a particular model should be established in planning documents before developing or using the model. 
4.6.3 Data from field observations and experimental measurements used to validate models must be independent of the data used to develop the model (IAEA 1989). The model is calibrated with the original data set during development. Adjustments are made in the model structure and/or parameter values to obtain a more perfect fit to the data and to more accurately describe the physical system. After the calibration has been done, it should not be repeated during validation, to accurately judge the performance of the calibrated model with an independent data set. The validation process should be repeated as many times as necessary to cover the range of conditions over which the model may be used.

4.6.4 IAEA (1989) presents examples of statistical validation techniques for deterministic and probabilistic models, together with an example of the application of regression analysis for validation. EPA (1985) presents a method for validating chemical exposure and hazard assessment models that uses extensive statistical testing of a subjectively determined null hypothesis.

4.6.5 The degree of software validation necessary for a given situation may be determined by an independent assessment by someone familiar with the model application, particularly for models involving inadequately defined parameters controlling groundwater flow and contaminant transport (ASME 1989b). Validation (and verification) of software must be performed by persons other than those who developed the software (ASME 1990).

4.6.6 To address the above requirements for models developed by SNL, the extent of validation necessary for a particular model is determined by various personnel guiding the model's development and usage, and is based on the classification of the model and the analysis for which it will be used. The analysis is defined as the rational investigation of a natural or artificial phenomenon to discover principles that underlie the phenomenon (SNL 1992). Because knowledge of the system being modeled can change over time, model validation is treated as an ongoing process. A variety of additional personnel are also consulted during the planning of an analysis, during objective reviews of the analysis, and during the review of the final report of an analysis ISNL 
1992), to determine the extent of validation necessary.

4.6.7 Two general techniques are used by SNL for model validation: process validation and matching previous uncontrolled observations. Process validation involves either simulating short-term laboratory experiments under controlled conditions or using analogy with a similar and previously validated conceptual and mathematical model (SNL 1992). The technique of matching or collaborating previous uncontrolled observations (also described as calibration and history matching) refers to fitting parameters into computational models to reproduce uncontrolled historical data or partially controlled field data to some subjective level of accuracy. Calibration helps the analyst develop insight into the natural system and ultimately increases confidence in the applied model of the system. Calibration may be an important part of the validation process, but it is usually not the entire process because of the uncertainties associated with calibration. For example, many false combinations of parameters may be selected and still reproduce the correct model result. The validation process also includes review of process models by knowledgeable peers during analysis workshops and technical reviews (SNL 1992).

\subsection{Model Documentation}

\subsubsection{Model Documentation Package Elements}

The USGS suggests that a groundwater model documentation package include the following elements (McLean 1983):

- Model objective

- Conceptual model description

- Mathematical model description

- Model calibration

- Model sensitivity 
- Model limitations

- Model conclusions.

Although the SNL WIPP performance assessment model encompasses many parameters in addition to groundwater movement, the USGS recommendations serve as a helpful comparative tool.

\subsubsection{Model Objective}

The USGS suggests that the model objective state the problem the model will solve. For example, if the objective is to estimate contaminant transport through the Salado formation, the result might be contaminant concentration at a receptor well. SNL includes a model objective in all formal reports for Class $A$ and $C$ analyses (SNL 1992) to address this.

\subsubsection{Conceptual Model Description}

The conceptual model describes the processes and geometry of a real system being modeled in simplified terms, because all aspects of the system may not be relevant to the analysis. The conceptual model description should include the physical description of the modeled site, the physical parameters associated with that site, the basic equations used to describe the site, and the fundamental assumptions used (i.e., two-dimensional versus three-dimensional system). The EPA (1991) suggests that the description include the spatial boundaries of the model and the time period it covers. The parameters and the assumptions used to determine those parameters should be given. For example, "the transmissivity of the formation was estimated from the results of 15 pump tests performed at five different wells on the site." SNL addresses these suggestions for Class $A$ and $C$ analyses by including descriptions of the conceptual model, the corresponding assumptions and limitations, the input data sources, and the initial and boundary conditions for the model in formal reports (SNL 1992).

\subsubsection{Mathematical Model Description}


The mathematical model description explains the conceptual model with a set of governing equations, which are translated into the simulation code. The mathematical model should be described and documented to show that it implements the conceptual model correctly and can be understood and used by others. Although various planning documents should have been used during the development of the code, these are outside the scope of this report. This report focuses on the documents that must be available for users and others who need to analyze the credibility of a model's results.

The description of the model used to implement the conceptual model and solve the stated problem should include the following:

- The model grid and its boundaries (McLean 1983)

- The governing equations that are the basis for the model (EPA 1991)

- The mathematical method used to solve the equations (EPA 1991)

- Instructions for preparing input files and interpreting output files (ASME 1990; ANSI/IEEE 1989)

- A user's manual for model users and programmers (ASME 1990).

Code documentation should include a list of error messages for anticipated problems and suggested corrections which may address the error (ANSI/IEEE 1989). Users who encounter serious problems should have a contact for questions, updates, and maintenance support (ASME 1990).

SNL addresses the above requirements in its QA program. Class $A$ computer codes developed at SNL are documented with user manuals that include the model theory and the numerical solution techniques used to solve the system of equations. They also have on-line help files that a user can access while operating the code. Input data, 
unique analysis results, and model codes are archived at the request of the analyst for Class $\mathrm{C}$ software and automatically for Class $\mathrm{A}$ software. The archived magnetic tapes or optical disks are stored in the SNL configuration management software (SNL 1992).

\subsubsection{Model Calibration, Verification, and Validation}

The required documentation for anyone who needs to evaluate the credibility of the model results includes the following:

- A copy of the source code (EPA 1991)

- The basis for code calibration (McLean 1983)

- Example problems and their complete input/outputs (EPA 1991)

- The code verification and validation report (ASME 1990; ANSI/IEEE 1989)

- A management plan for controlling, implementing, and reporting code changes (ANSI/IEEE 1989).

Model reviewers require a copy of the source code to examine code structure, programming language efficiency, adherence to programming standards, and internal comments that document the code (EPA 1991). The code calibration process should include the criteria that were used to adjust input parameters to produce model results close to measured results (McLean 1983). The code verification and validation report must describe the method used to verify that the model requirements have been approved by the appropriate authority, the conceptual model meets the problem requirements, and the code implements the conceptual model (ANSI/IEEE 1989). In addition, this report should show that the executed code complies with the model requirements. The management plan controls future code development by describing the method for identifying code errors or desired improvements, how these software changes are implemented, and how the changed code is documented and distributed to the users. 
The verification and validation report must include the following information (ASME 1989a; ASME 1990):

- The computer program tested

- The computer hardware used for the test

- The hardware and software required to run the model

- Any required test equipment and calibrations

- The test date

- The name of the person who tested the code or recorded the data

- Applicable models used

- Descriptions of the test problems and the expected results

- Program test results and whether the difference between the test and expected results is acceptable

- The results of all software reviews and tests

- Any recalibration done for the code if the test results deviated significantly from the expected results

- The current code status

- The name of the person who evaluated the results.

The software QA procedures at SNL require records on code changes and code verification. These records are stored in the SWCF. The user's manual includes at least one sample problem; the SNL Compliance Assessment Methodology CONtroller (CAMCON) software controls the library of model subroutines, stores the on-line documentation for each code, stores site-specific data in a database, 
and archives input files with internal comments that include the analyst, model run purpose, and the date (SNL 1992).

\subsubsection{Model Sensitivity}

After the mathematical code that implements the conceptual model has been developed, documented, and calibrated, the model's sensitivity should be evaluated. This evaluation includes estimating the effects of changes in the input parameters on the model results. The initial assumptions should also be re-evaluated to ensure that they are consistent with the results predicted by the model. For example, if groundwater was assumed to flow horizontally, but the model predicts fractures will occur, then that assumption should have been changed in the code. The model may also be sensitive to the specified boundaries defined in the code. If a discharging boundary becomes a recharging boundary during initial model runs, then that change should be reflected in the code. Although model sensitivity is not discussed in either SNL QA report reviewed, it is discussed in the annual performance assessment report prepared by SNL.

\subsubsection{Model Limitations}

The model description should include the limitations on the application of the model. The model is essentially limited by its unique features. For example, if the model relies upon the assumption that a formation is homogeneous, then obviously the model should be limited to use at relatively homogeneous sites and should not be applied to known heterogeneous sites. If the model describes a particular site or contaminant specifically, then it may not describe transport mechanisms that are critical for other sites or contaminants. Formal reports for SNL Class $A$ and $C$ analyses include descriptions of the model assumptions and limitations (SNL 1992).

\subsubsection{Model Conclusions}

The original conceptual model may have been revised if the initial result was not an accurate prediction of the physical system. Each revision to the conceptual model is an important part of modeling the 
problem.

At SNL, the assumptions made, the data and software (program and version) used, the analysis results obtained, and any conclusions based on those results are documented for any conceptual model generated. This information is recorded informally in analysis notebooks as the analysis progresses and is provided in formal reports for Class $A$ and $C$ analyses. Other information provided in the formal reports are the model purpose, underlying assumptions of the conceptual model, the model's limitations and application, and the conceptual and mathematical model validation. These reports will be kept in the SWCF until a waste retrieval decision is made. The model is subject to an analysis review workshop with the peers of the model creator or an expert judgment panel. The comments from this workshop are kept as QA records in the SWCF for Class A and C documentation (SNL 1992). 


\subsection{Discussion}

5.1 In comparing the software development QA processes as described in the references examined, the major discrepancy between the standardized (i.e., ASME, ANSI/IEEE, DOE, IAEA) and EPA-recommended techniques and the methodology used by SNL was in model validation. Specifically, IAEA (1989) states that model calibration should not be performed during validation. SNL (1992) describes calibration as an integral part of the model's validation. However, because of the uncertainties associated with calibration, it is only a part of overall software validation at SNL. Software validation also includes validation of the conceptual process models by knowledgeable peers to ensure that the model describes the natural system with "sufficient accuracy," which is a subjective measure. Model sensitivity is also not mentioned in the SNL QA reports reviewed, but may be described as part of parameter QA programs, because it is discussed in annual performance assessment reports.

5.2 For many aspects of software development (e.g., verification, the use of classification systems, documentation), no standardized techniques are presented in the literature reviewed. Rather than using this lack of techniques as a justification to develop an internal software development program lacking rigor, SNL has a well-developed system of documentation, verification, and validation for models that is rigorous in its expectations (see SNL 1991 for complete description). Without examining the SNL program in detail, which would require a full-scale audit of the SNL model QA program, it appears that the SNL system as documented (SNL 1991; SNL 1992) is sufficient to ensure the quality of the models being developed.

5.3 The description of personnel and their responsibilities provided in the referenced SNL documents is an example of the degree of detail in the SNL model QA program. Although it would seem the same level of quality could be accomplished using fewer personnel or less extensive oversight, the SNL program accounts for a multilayer review of the software's application for a particular purpose. The review process itself also appears to be well documented in reports that are kept for the duration of the WIPP project. 
5.4 This discussion is not intended to say, and should not be construed to say, that software developed under the SNL model QA system is above reproach and should not be examined independently (through peer review) before use. Because the system used to develop a model may be beyond censure does not mean that the model is as credible. Instead, the extensive internal review, verification, and validation process in place at SNL would expedite such a review through the availability of documentation on the software's development.

5.5 One aspect related to software development but perhaps not met by SNL is the requirement for transportability of a model. According to DOE (1990), "Sites are encouraged to adopt those computer hardware and system software standards which will facilitate the transportability of application software." Because the models being developed by SNL for the WIPP performance assessment were originally intended to solve specific problems for a single customer (DOE), the portability of the software was not treated as an absolute requirement. Rather, this aspect of model development has been addressed only as needed by the task leader of a model development project (SNL 1991). 


\subsection{Recommendations and Future Plans}

6.1 The QA program for WIPP performance assessment modeling as described in the SNL reports reviewed (SNL 1991; SNL 1992) depicts a rigorous system for software development and use. The most rigorous $Q A$ program, however, is only effective if it is being properly followed by all participants. DOE headquarters have recently audited SNL'S QA program for the WIPP performance assessment process. This audit included review of software, analysis, and parameter QA procedures. Software test traceability, software change control, and software version identification needed improvement according to the draft audit report (SNL 1993). Documentation that has been developed during peer reviews, analysis workshops, and other technical forums should be reviewed independently to ensure that the $Q A$ program is being fully implemented. This review should also analyze any internal audit reports to evaluate the effectiveness of the internal audit controls.

6.2 Currently, nearly all the software submodules are classified as Class $C$ or Class $X$ (SNL 1993). Class $A$ is necessary for models that will determine regulatory compliance. SNL expects to complete Class A documentation, verification, and validation for the final model submodules by 1996; reviews and documentation required to upgrade these submodules to Class A should be expedited to ensure completion prior to regulatory compliance evaluation.

6.3 The linked DAM/TOUGH2 model has been mentioned as a code for verifying and validating certain submodules of the SNL WIPP model. Most of the QA requirements for the component codes - DAM and TOUGH2 have been met by their developers. Extensive documentation and verification data are available for the DAM in calculation briefs prepared by International Technology Corporation and reports of the Engineered Alternatives Task Force. Users' manuals and other research publications provide extensive verification and validation data for TOUGH2. However, model linking has resulted in significant changes to the DAM, so the linked model will require additional documentation regarding usage and verification. The linked computational model is still under development, so $Q A$ requirements cannot be fulfilled at this time. If the linked 
Quality Assurance Criteria for WIPP

DOENIPP-95-2050

Performance Assessment Modeling

Page 24 of 26

DAM/TOUGH 2 module is to be used for verification and validation of any SNL submodules, it should also meet all Class $A$ QA requirements as described in this report. 
Quality Assurance Criteria for WIPP

\section{Appendix A - List of References}

Code of Federal Regulations (CFRs):

Title 40 CFR Part 191 (40 CFR 191), Environmental Radiation Protection Standards for the Management and Disposal of Spent Nuclear Fuel, HighLevel and Transuranic Radioactive Wastes (December 1993)

40 CFR 268, Land Disposal Restrictions (August 1993)

American National Standards Institute/Institute of Electrical and Electronics Engineers (ANSI/IEEE) Standards:

ANSI/IEEE Standard 1012, IEEE Standard for Software Verification and Validation Plans (1986)

ANSI/IEEE Standard 1008, IEEE Standard for Software Unit Testing (1987)

ANSI/IEEE Standard 730.1, IEEE Standard for Software Quality Assurance Plans (1989)

\section{American Society of Mechanical Engineers (ASME) Programs:}

ASME NOA-1, Quality Assurance Program Requirements for Nuclear Facilities, Supplement 11S-2, Supplemental Requirements for Computer Program Testing (1989a)

ASME NQA-3, Quality Assurance Program Requirements for the Collection of Scientific and Technical Information for Site Characterization of High-Level Nuclear Waste Repositories (1989b)

ASME NQA-2a, Quality Assurance Program Requirements for Nuclear Facility Applications (1990)

\section{Environmental Protection Agency (EPA) Guidance:}

EPA/600/D-85/297, Validation Methods for Chemical Exposure and Hazard Assessment Models (1985)

EPA Quality Assurance Guidelines for Modeling Development and Application Projects, a Policy Statement (1991) 
SAND 90-1240, Quality Assurance Procedures for Computing Software Supporting Performance Assessments of the Waste Isolation Pilot Plant (1991)

SAND 91-0428, Quality Assurance Procedures for Analyses and Report Reviews Supporting Performance Assessments of the Waste Isolation Pilot Plant (1992)

Waste Isolation Pilot Plant Technical Progress Report (November 1993)

\section{Other Documents:}

Federal Register (FR) 59 FR 15843, Nuclear Safety Management (April 5, 1994)

Department of Energy (DOE) Order 1330.1D, Computer Software Management

International Atomic Energy Agency (IAEA) Safety Series Number 100, Evaluating the Reliability of Predictions Made Using Environmental Transfer Models (1989)

McLean, John S., Memorandum to Chief, Hydrologic Investigations Section, United States Department of the Interior, Geological Survey (October 3, 1983) 